\title{
Modeling risk and uncertainty in designing reverse logistics problem
}

\author{
Aida Nazari Gooran ${ }^{a}$, Hamed Rafiei ${ }^{a^{*}}$ and Masoud Rabani ${ }^{b}$ \\ ${ }^{a}$ Department of Industrial Engineering, College of Farabi, University of Tehran, Iran \\ ${ }^{b}$ School of Industrial Engineering, College of Engineering, University of Tehran, Tehran, Iran \\ C H R O N I C L E \\ Article history: \\ Received September 16, 2016 \\ Received in revised format: \\ October 22, 2016 \\ Accepted May 1, 2017 \\ Available online \\ May 1, 2017 \\ Keywords: \\ Reverse logistic \\ Uncertainty \\ Risk \\ Conditional value at risk \\ Chance-constrained

\section{A B S T R A C T} \\ Increasing attention to environmental problems and social responsibility lead to appear reverse \\ logistic (RL) issues in designing supply chain which, in most recently, has received \\ considerable attention from both academicians and practitioners. In this paper, a multi-product \\ reverse logistic network design model is developed; then a hybrid method including Chance- \\ constrained programming, Genetic algorithm and Monte Carlo simulation, are proposed to \\ solve the developed model. The proposed model is solved for risk-averse and risk-seeking \\ decision makers by conditional value at risk, sum of the excepted value and standard deviation, \\ respectively. Comparisons of the results show that minimizing the costs had no direct relation \\ with the kind of decision makers; however, in the most cases, risk-seeking decision maker \\ gained more return products than risk-averse ones. It is clear that by increasing returned \\ products to the chain, production costs of new products and material will be reduced and also \\ by this act, environmental benefits will be created.
}

programming

Monte Carlo simulation

Genetic algorithms

\section{Introduction}

Nowadays, designing reverse logistics plays an important role in gaining competitive advantages (Tonanont et al., 2008). There are different definitions for reverse logistics but According to Salema et al. (2007) reverse logistics (RL) is defined as "The process of planning, implementing and controlling the efficient, effective inbound flow and storage of secondary goods and related information opposite to the traditional supply chain directions for the purpose of recovering value and proper disposal".

It is worth to mention that, unlike traditional supply chain, RL has an uncertainty inherent such as quality, price, time and amounts of return products (Soleimani \& Govindan, 2014). These nature uncertainties imposes a high degree of complexity in RL design (Babazadeh et al., 2015). In order to optimize networks, there are some methods that include RL under uncertainty represented in Table 1.

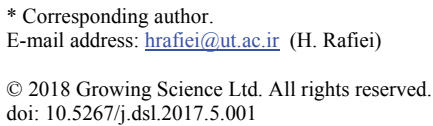


Table 1

Some methods of dealing with uncertainty in the networks which include RL

\begin{tabular}{ll}
\hline Reference & Methods \\
\hline (Lee \& Dong, 2009) & Stochastic programming and simulated annealing \\
(Pishvaee et al., 2011) & Robust optimization \\
(Jindal et al., 2015) & Fuzzy \\
(Khatami et al., 2015) & Benders' decomposition \\
\hline (Vahdani \& Mohammadi, 2015) & Interval-stochastic robust optimization \\
\hline
\end{tabular}

Beamon (1999) and Fleischmann, et al. (2000) are some of fundamental papers in reverse logistics. Beamon proposed a conceptual framework for different types of chain (forward, reverse and CLSC) and evaluated environmental factors in RL and CLSC and also introduced customer satisfaction, service or responsiveness and costs as important performance measures in evaluating the supply chain. Fleischmann, et al. (2000) studied product recovery networks and identified general characteristics and compared them with others logistics networks. They also stated that existing uncertainty in these networks are the major distinct between these networks and traditional one. Pokharel and Mutha (2009) and Govindan et al. (2015) proposed a comprehensive review to draw a framework of the past papers until 2013. They also stated that RL networks must be designed with the goal of gaining returned products in expected time, price and quantities to the chain. Based on Govindan et al. (2015), price, demand and costs are important parameters used frequently in related studies as uncertainty parameters and there is a lack of reverse logistics models with various risk parameters.

Table 2

Network structure codes

\begin{tabular}{llll}
\hline Layers of network & Code & Layers of network & Code \\
\hline Inspection & $\mathrm{I}$ & Raw material market & R.M.M \\
Disassembling & $\mathrm{Da}$ & Recovery & Rec \\
Refurbishing & $\mathrm{Rf}$ & Customer zone & $\mathrm{Cu} . \mathrm{Z}$ \\
Recycling & $\mathrm{R}$ & Customer & $\mathrm{Cu}$ \\
Plastic recycling & $\mathrm{P} . \mathrm{R}$ & Return & $\mathrm{Ret}$ \\
Steel recycling & $\mathrm{S} . \mathrm{R}$ & Manufacture & $\mathrm{M}$ \\
Disposal & $\mathrm{Di}$ & Remanufacture & $\mathrm{Rm}$ \\
Regions & $\mathrm{Re}$ & Processing & $\mathrm{P}$ \\
Collection & $\mathrm{C}$ & Market & $\mathrm{Ma}$ \\
Sorting & $\mathrm{S}$ & Second market & $\mathrm{S} . \mathrm{M}$ \\
Refinery & $\mathrm{Ref}$ & Distribution & Dis \\
Warehouse & $\mathrm{W}$ & Factory & $\mathrm{F}$ \\
Disposer market & $\mathrm{D} . \mathrm{M}$ & Reuse market & $\mathrm{Ru} . \mathrm{M}$ \\
Reprocessing & R.P & & \\
\hline
\end{tabular}

Nikolaou et al. (2013) developed a framework to measure reverse logistics social responsibility based on the Triple Bottom Line approach. Benedito and Corominas (2012) formulated a Markov decision problem in order to minimize total cost with regard to stochastic demand and return and limited manufacturing and storage capacities. To structure the literature review of RL problem and in order to show difference of this paper from the others, Table 4 is prepared. The codes of this Table are given in Table 2 and Table 3. By investigating Table 3 research gaps can be found in the papers that have been published in reverse logistics field, for example, this table indicates that minimizing total costs or maximizing profit is the main goal that is pointed to in most of the papers and maximizing return products to the chain rarely be considered in literature. Most of the papers have designed RL in certain mode or have considered uncertain parameters such as demand, Return quantity and quality in their model and few of them have evaluated risks in their RL network. 
Table 3

Parameters codes

\begin{tabular}{llll}
\hline Parameters & Code & Parameters & Code \\
\hline Return quantity & R.Qn & Fixed cost & F.C \\
Return quality & R.Qa & Amount of return & AOR \\
Sorting ratio & S.R & Remanufacturing rate & Rm.R \\
Transportation cost & T.C & Recycling rate & R.R \\
Demand & D & disposal rate & Di,R \\
Rate of return & ROR & Return & R \\
Timing of returned products & T.R & & \\
\hline
\end{tabular}

To the best of the authors' knowledge there has been no paper that simultaneously considering uncertainty and risk parameters in the modeling RL. Therefore, the present paper focuses on designing and planning a reverse logistic network with the goal of maximizing return products to the chain and minimizing total cost, influenced by uncertainty rate of return, quality and quantity of returned products and risks related to demand, remanufacturing, recycling and disposal rate. To this end a combination of chance constraining, genetic algorithm, and Monte Carlo simulations is used. This method was first provided by Dai and Zheng (2015) to solve their closed-loop supply chain under uncertainty of final product price. In fact, the reason for choosing this hybrid method is assessment capabilities that are existing in chance-constraint and Monte Carlo simulations method. In order to create a comprehensive model, this paper considered two kinds of decision maker that means risk seeking and risk averse.

Table 4

Modeling approach and network structure of the reviewed works

\begin{tabular}{|c|c|c|c|c|c|c|}
\hline \multirow[t]{2}{*}{ Reference } & \multicolumn{2}{|c|}{ Objective Function } & \multicolumn{2}{|c|}{ Parameters } & \multicolumn{2}{|c|}{ Chain centers } \\
\hline & Max & Min & Uncertain & Risk & single & Hybrid \\
\hline (Min et al., 2006) & - & Total cost & - & - & $(\mathrm{Cu}), \mathrm{C},(\mathrm{Ret})$ & - \\
\hline (Salema et al., 2007) & - & Total cost & $\mathrm{D}, \mathrm{R}$ & - & $\begin{array}{c}\mathrm{F}, \mathrm{W},(\mathrm{Cu}), \\
(\mathrm{Da})\end{array}$ & (F/Di) \\
\hline (Lieckens \& Vandaele, 2007) & - & Total cost & $\begin{array}{c}\text { (R.Qn ), } \\
\text { (R.Qa), (T.R) }\end{array}$ & - & $\begin{array}{c}\text { (Ru.M), } \\
\text { (D.M), (Rec), }\end{array}$ & - \\
\hline (Kara \& Onut, 2010) & profit & - & $\mathrm{D},(\mathrm{AOR})$ & - & $\mathrm{R},(\mathrm{Di}),(\mathrm{Cu})$ & - \\
\hline (Tuzkaya et al., 2011) & $\begin{array}{l}\text { weighted product } \\
\text { volume }\end{array}$ & Total cost & - & - & $\begin{array}{l}(\mathrm{Cu}), \mathrm{C},(\mathrm{Ret}), \\
\mathrm{M},(\mathrm{Ma}),(\mathrm{Di}), \\
\text { (S.M) }\end{array}$ & - \\
\hline (Alumur et al., 2012) & profit & - & - & - & $\mathrm{R}$ & $\begin{array}{l}\text { (I/Da), } \\
(\mathrm{Rm} / \mathrm{Rf})\end{array}$ \\
\hline (Diabat et al., 2013) & - & Total cost & - & - & $(\mathrm{Cu}), \mathrm{C},(\mathrm{Ret})$ & - \\
\hline (Roghanian \& Pazhoheshfar, 2014) & - & Total cost & $\mathrm{D}$ & - & $\begin{array}{l}\mathrm{M}, \mathrm{R}, \mathrm{P},(\mathrm{Da}), \\
\text { (Ret) }\end{array}$ & - \\
\hline (Ene \& Öztürk, 2014) & profit & - & - & - & $\begin{array}{c}\text { (Cu), C, (R.P), } \\
\text { (Di), R, (S.M), } \\
\text { M }\end{array}$ & - \\
\hline (Ayvaz et al., 2015) & profit & - & $\begin{array}{c}\text { (R.Qn), } \\
\text { (S.R), (T.C) }\end{array}$ & - & $\begin{array}{l}\text { (Re), C, S, R, } \\
\quad \text { (Ref), } \\
\text { (R.M.M), (Di) }\end{array}$ & - \\
\hline (Babazadeh et al., 2015) & - & $\begin{array}{c}\text { CVaR in the total } \\
\text { cost }\end{array}$ & $\begin{array}{l}\text { (R.Qn), } \\
\text { (R.Qa) }\end{array}$ & & $\begin{array}{c}(\mathrm{Rec}), \mathrm{C} \\
(\mathrm{Cu} . \mathrm{Z}),(\mathrm{Di})\end{array}$ & - \\
\hline (Govindan et al., 2016) & $\begin{array}{c}\text { Social } \\
\text { responsibility }\end{array}$ & $\begin{array}{l}\text { Present value of } \\
\text { cost and } \\
\text { environmental } \\
\text { impacts }\end{array}$ & $\begin{array}{l}\mathrm{D},(\mathrm{ROR}), \\
\quad(\mathrm{F} . \mathrm{C})\end{array}$ & - & $\begin{array}{c}(\mathrm{Cu} . \mathrm{Z}), \mathrm{C}, \\
\text { (P.R), (S.R) }\end{array}$ & - \\
\hline This paper & $\begin{array}{l}\text { return products to } \\
\text { the chain }\end{array}$ & Total costs & $\begin{array}{l}\text { (ROR), } \\
\text { (R.Qn), } \\
\text { (R.Qa) }\end{array}$ & $\begin{array}{l}\text { D, }(\mathrm{Rm} . \mathrm{R}), \\
\text { (R.R), } \\
\text { (Di.R) }\end{array}$ & $\begin{array}{l}(\mathrm{Cu} . \mathrm{Z}), \mathrm{R}, \\
(\mathrm{Rm}),(\mathrm{Di})\end{array}$ & $\begin{array}{l}\mathrm{C},(\mathrm{Da}), \\
\text { (Dis) }\end{array}$ \\
\hline
\end{tabular}

The remainder of the paper is structured as follow: section 2 presents mathematical model for designing RL network. The proposed hybrid solution approach and computational sensitivity analysis is provided in section 3. Finally, the paper is concluded in section 4. 


\section{The proposed mathematical model}

In this section, a RL network problem with hybrid distribution-collection-disassemble (hereafter called HC.C.D.D) is designed based on Fig. 1. In this network, used products from customers are transferred to collection centers and after that, they undergo being disassembled and finally in terms of the quality of used products (A, B and C), are send back to remanufacturing, recycling and disposal centers, respectively.

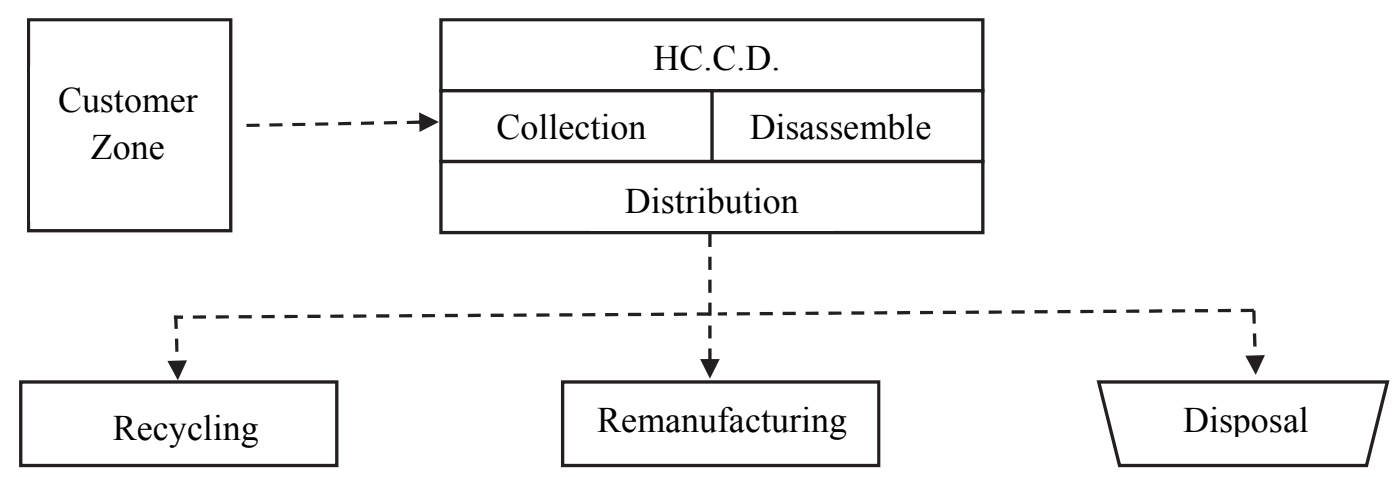

Fig. 1. Proposed structure of closed-loop supply chain network design

Based on Fig. 3, the following notations are introduced for formulating the model.

Sets:

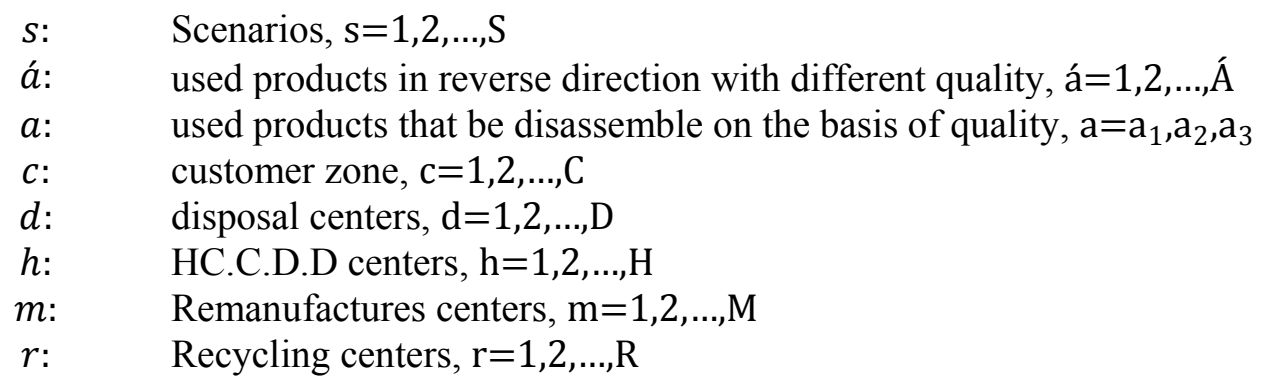

\section{Variables:}

$X_{\text {chás }}: \quad$ Quantity of used products (á) transferred from customer zone C to HC.C.D.D center h, over scenario $s$

$\alpha_{h m a_{1} s}: \quad$ Quantity of remanufacturing products $\left(a_{1}\right)$ transferred from HC.C.D.D center $\mathrm{h}$ to Remanufactures centers $\mathrm{m}$, over scenario $\mathrm{s}$

$\beta_{\mathrm{hra}_{2} \mathrm{~s}}$ : Quantity of recycling products $\left(a_{2}\right)$ transferred from HC.C.D.D center $\mathrm{h}$ to Recycling centers $r$, over scenario s

$\gamma_{h d a_{3} s}: \quad$ Quantity of disposal products $\left(a_{3}\right)$ transferred from HC.C.D.D center $\mathrm{h}$ to disposal center d, over scenario $\mathrm{s}$

$N S_{\text {chás }}: \quad$ Quantity of non- satisfied demand of customer 1

$Q_{h}$ : $\quad$ Binary variable that show HC.C.D.D center $h$ is open (equals to 1 ) or close (equals to 0).

$Q_{m}$ : $\quad$ Binary variable that show Remanufactures centers $m$ is open (equals to 1 ) or close (equals to 0 ).

$Q_{d}$ : $\quad$ Binary variable that show disposal center $\mathrm{d}$ is open (equals to 1 ) or close (equals to 0$)$. 
$Q_{r}: \quad$ Binary variable that show Recycling centers $r$ is open (equals to 1 ) or close (equals to 0 ).

\section{Parameters:}
$d e_{\text {chás }}^{T}:$
Demand of final products (á) that customer zone c, request from HC.C.D.D center h, over scenario s
$x r_{\text {chás }}^{T}:$
Return rate of
over scenario $s$
$\operatorname{Car}_{r a_{2} s}:$
recycling capacity of center $r$, for recycling raw material $\left(b_{2}\right)$,over scenario $\mathrm{s}$, in reverse flow
$\operatorname{Cam}_{m a_{1} s}:$ remanufacturing capacity
scenario $\mathrm{s}$, in reverse flow

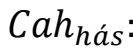
scenario s, in reverse flow
collection capacity of HC.C.D.D center h, for used products (á), over scenario s, in reverse flow
$\operatorname{Cad}_{\mathrm{da}_{3} \mathrm{~s}}$ : Disposal capacity (center $\mathrm{d}$ ), for returned products $\left(\mathrm{a}_{3}\right)$, over scenario $t$, in reverse flow
$F H_{h}$ : Fixed cost of opening HC.C.D.D center h
$F M_{m}: \quad$ Fixed cost of opening Remanufactures centers $\mathrm{m}$
$F R_{r}: \quad$ Fixed cost of opening Recycling centers $\mathrm{r}$
$F D_{d}: \quad$ Fixed cost of opening disposal center d
$C N S_{\text {chás }}$ : Penalty cost per unit of non- satisfied demand of customer zone c, for final products (á) that request from HC.C.D.D center h, over scenario s.
$V X_{\text {chás }}: \quad$ Unit Variable cost for products (á) shipped from customer zone c, to HC.C.D.D center h, over scenario s
$V \alpha_{h m a_{1} s}: \quad$ Unit Variable cost for products $\left(a_{1}\right)$ shipped from HC.C.D.D center h to
Remanufactures centers $\mathrm{m}$, over scenario $\mathrm{s}$
$V \beta_{h r a_{2} s}$ : Unit Variable cost for products $\left(a_{2}\right)$ shipped from HC.C.D.D center $h$ to
Recycling centers $r$, over scenario $s$
$V \gamma_{h d a_{3} s}: \quad$ Unit Variable cost for products $\left(a_{3}\right)$ shipped from HC.C.D.D center $\mathrm{h}$ to disposal center $\mathrm{d}$, over scenario $\mathrm{s}$
$\operatorname{rom}_{h m a_{1} s}^{T}$ : Rate of remanufacturing used products $\left(a_{1}\right)$ from HC.C.D.D center $\mathrm{h}$ to Remanufactures centers $\mathrm{m}$, over scenario $\mathrm{s}$
ror $_{\text {hra }}^{T}$ S $: \quad$ Rate of recycling used products $\left(a_{2}\right)$ from HC.C.D.D center h to Recycling centers $r$, over scenario $s$
$\operatorname{rod}_{h d a_{3} s}^{T}: \quad$ Rate of disposal used products $\left(a_{3}\right)$ from HC.C.D.D center h to disposal center $\mathrm{d}$, over scenario $\mathrm{s}$
$p_{s}$ : $\quad$ Occurrence probability of scenario $\mathrm{s}$

The multi-objective, multi-echelon, multi-product reverse logistic network design problem can be modeled by above-mentioned notations under risk and uncertainty parameters that the terms Eqs. (120) indicate this modeling.

\section{Objective functions}

$$
\begin{aligned}
& \max Z_{1}^{T}=\sum_{c} \sum_{h} \sum_{a} \sum_{s}\left(x r_{\text {chás }}^{T} *\left[\left(d e_{\text {chás }}^{T}-N S_{\text {chás }}\right)\right]\right) \\
& \min Z_{2}=\sum_{s=1}^{S} p_{s}\left[\left(\sum_{c} \sum_{h} \sum_{a} \sum_{s}\left(X_{\text {chás }} * V X_{\text {chás }}\right)\right)+\left(\sum _ { h } \sum _ { m } \sum _ { a _ { 1 } } \sum _ { s } \left(\alpha_{h m a_{1} s} *\right.\right.\right. \\
& \left.\left.V \alpha_{h m a_{1} s}\right)\right)+\left(\sum_{h} \sum_{r} \sum_{a_{2}} \sum_{s}\left(\beta_{h r a_{2} s} * V \beta_{h r a_{2} s}\right)\right)+\left(\sum_{h} \sum_{d} \sum_{a_{3}} \sum_{s}\left(\gamma_{h d a_{3} s} * V \gamma_{h d a_{3} s}\right)\right)+ \\
& \left.\sum_{c} \sum_{h} \sum_{\dot{a}} \sum_{s} N S_{c h a ́ s} C N S_{c h a ́ s}\right]+\left(\sum_{h} F H_{h} Q_{h}+\sum_{m} F M_{m} Q_{m}+\sum_{r} F R_{r} Q_{r}+\sum_{d} F D_{d} Q_{d}\right)
\end{aligned}
$$




\section{Constraints}

$$
\begin{aligned}
& X_{\text {chás }}=x r_{\text {chás }}^{T} *\left[\left(d e_{\text {chás }}^{T}-N S_{\text {chás }}\right)\right] \\
& \sum_{i} \alpha_{h m a_{1} s}=\sum_{i} \operatorname{rom}_{h m a_{1} s}^{T} * \sum_{l} X_{\text {chás }} \\
& \sum_{s} \beta_{\text {hra }_{2} s}=\sum_{s} \operatorname{ror}_{\text {hra }_{2} s}^{T} * \sum_{l} X_{\text {chás }} \\
& \forall s \\
& \forall t, j, q_{2}, \dot{q} \\
& \sum_{k} \gamma_{h d a_{3} s}=\sum_{k} \operatorname{rod}_{h d a_{3} s}^{T} * \sum_{l} X_{\text {chás }} \\
& \forall t, j, q_{3}, q \\
& \sum_{j} \operatorname{rom}_{h m a_{1} s}^{T} * \sum_{j} \alpha_{h m a_{1} s} \leq \operatorname{Cam}_{m a_{1} s} * Q_{m} \\
& \forall i, p_{2}, q_{2}, t \\
& \sum_{j} \operatorname{ror}_{h r a_{2} S}^{T} * \sum_{j} \beta_{\mathrm{hra}_{2} \mathrm{~S}} \leq \operatorname{Car}_{\mathrm{ra}_{2} \mathrm{~S}} * Q_{r} \\
& \sum_{j} \operatorname{rod}_{h d a_{3} s}^{T} * \sum_{j} \gamma_{h d a_{3} s} \leq \operatorname{Cad}_{\mathrm{da}_{3} \mathrm{~s}} * Q_{d} \\
& \forall s, r_{2}, q_{3}, t \\
& \forall k, q_{4}, t \\
& \sum_{l} X_{\text {chás }} \leq \operatorname{Cah}_{\text {hás }} * Q_{h} \\
& \forall j, q, t
\end{aligned}
$$

The first objective function (1) seeks to maximize return products to supply chain. The second objective function (2) minimizes total costs of the supply chain. The second objective function includes variable cost, penalty cost of non-satisfied demands and fixed cost of opening the centers of supply chain by the first four terms, the fifth and the last four ones, respectively.

Constraint (3) addresses quantity of the return products that customer zone sent back to HC.C.D.D centers at the end of product's life. Constraints (4-6) refer to the quantity of used products shipped from HC.C.D.D to remanufacturing, recycling and disposal centers, respectively to become recoverable. Constraints (7-10) impose the capacity restrictions on the located facilities. Constraint (11-18) impose the upper and lower bound of locating the centers and finally, Constraint (19 and 20) refer to the binary and decision variables and their restrictions.

\section{Experimental results}

In this section, validation of the model is determined by GAMS, with regard to input data shown in Table 5, for several random problems produced in Table 6 and finally, the results are represented in Table 7. Note that all of the parameters are assumed to be certain in Table 5. The GAMS results indicate that if constraint of locating centers is applied to model, lost sale will appear and conversely, if constraint of locating centers is not imposed, lost sales will be missed unless the number of HC.C.D.D centers was less than customer zones. Also, due to assumption that considered for Table 5 based on to be certain all the parameters, in each time that the software is run, the quantity of recycling and disposal (that indicates with $\gamma_{h d a_{3} s}$ and $\beta_{h r a_{2} s}$, respectively) are the same and lower than quantity of remanufacturing products (that indicates with $\alpha_{h m a_{1} s}$ ). 
Table 5

Input data of GAMS software

\begin{tabular}{|c|c|c|c|}
\hline parameters & The amount attributed & Parameters & The amount attributed \\
\hline$d e_{\text {chás }}^{T}$ & 115 & $F D_{d_{i}}$ & 300 \\
\hline$x r_{\text {chás }}^{T}$ & 0.3 & $V X_{\text {chás }}$ & 6 \\
\hline $\mathrm{Car}_{\mathrm{ra}_{2} \mathrm{~S}}$ & 1200 & $V \alpha_{h m a_{1} s}$ & 5 \\
\hline $\mathrm{Cam}_{m a_{1} s}$ & 800 & $V \beta_{h r a_{2} S}$ & 8 \\
\hline Cah hás & 1000 & $V \gamma_{h d a_{3} s}$ & 6 \\
\hline $\operatorname{Cad}_{\mathrm{da}_{3} \mathrm{~s}}$ & 1500 & $\operatorname{rom}_{h m a_{1} s}^{T}$ & 0.5 \\
\hline $\mathrm{FH}_{h}$ & 500 & $\operatorname{ror}_{h r a_{2} s}^{T}, \operatorname{rod}_{h d a_{3} s}^{T}$ & 0.25 \\
\hline$F M_{m}$ & 450 & $C N S_{c a ́}$ & 1000 \\
\hline$F R_{r}$ & 380 & & \\
\hline
\end{tabular}

Table 6

General information of the test problem to be solved by GAMS software

\begin{tabular}{ccccccc}
\hline $\begin{array}{c}\text { Number of } \\
\text { problem }\end{array}$ & $\begin{array}{c}\text { Recycling } \\
\text { centers }\end{array}$ & $\begin{array}{c}\text { Remanufacturing } \\
\text { centers }\end{array}$ & $\begin{array}{c}\text { HC.DA.RD } \\
\text { centers }\end{array}$ & Disposal & $\begin{array}{c}\text { Customer } \\
\text { zone }\end{array}$ & $\begin{array}{c}\text { Number } \\
\text { of } \\
\text { scenarios }\end{array}$ \\
\hline 1 & 3 & 4 & 3 & 3 & 2 & 2 \\
2 & 4 & 4 & 5 & 5 & 5 & 2 \\
3 & 6 & 5 & 7 & 4 & 7 & 3 \\
4 & 4 & 7 & 8 & 3 & 7 & 4 \\
5 & 9 & 5 & 9 & 7 & 9 & 3 \\
6 & 7 & 7 & 12 & 6 & 13 & 2 \\
\hline
\end{tabular}

Table 7

Results of deterministic model that solved by GAMS in randomly generated test problems

\begin{tabular}{llccccc}
\hline $\begin{array}{l}\text { constraint of } \\
\text { locating }\end{array}$ & $\begin{array}{l}\text { Number of } \\
\text { problem }\end{array}$ & $X_{\text {chás }}$ & $\alpha_{h m a_{1} S}$ & $\beta_{h r a_{2} S}$ & $\gamma_{\text {hda }} s$ & $N S_{\text {chás }}$ \\
\hline \multirow{3}{*}{ yes } & 1 & 276 & 138 & 69 & 69 & 1840 \\
& 2 & 690 & 345 & 172.5 & 172.5 & 11500 \\
& 3 & 1449 & 724.5 & 362.25 & 362.25 & 28980 \\
\multirow{2}{*}{ No } & 4 & 15456 & 7728 & 3864 & 3864 & 0 \\
& 5 & 16767 & 8383.5 & 4191.75 & 4191.75 & 0 \\
& 6 & 19734 & 9867 & 4933.5 & 4933.5 & 5980 \\
\hline
\end{tabular}

After evaluation and validation of the model under the certain mode, solution method must be proposed in order to solve the developed model under uncertain and risk mode. In 1959, Charnes and Cooper introduced chance-constrained programming to solve optimization problems under the variety uncertainties.

The general framework is as follow: (Mitra et al., 2008)

(1) $\min \left\{f(x) \mid h_{k}(x, \delta) \geq 0\right\}$

(2) $\min \left\{f(x) \mid \operatorname{pr}\left(h_{k}(x, \delta) \geq 0\right)>\beta\right\} \quad k=1, \ldots, u$

where, $f(x), x$ and $\delta$ are objective function, set of decision variables and set of random parameter, respectively and also, probability measure is shown by $p r$ and $p \in(0,1]$ shows probability level that must be satisfied for each constraint $\left(h_{k}(x, \delta)\right)$.

Since the paper of Soleimani and Kannan (2015), RL problems are classified as an NP-hard problem, therefore, it is appropriate to use Monte Carlo simulation as an effective tool for estimating expected value of uncertain parameters (Kamjoo et al., 2016) with genetic algorithm, in order to solve such the 
problems that have no analytical solution or it is gained hardly. Genetic algorithm includes the following main steps:

Initialization, evaluation, parent selection, reproduction and mutation. At the first, initial population must be generated randomly, after that, fitness value must be computed for each individual. In step 3, pairs of individuals are selected and crossover imposed on them. A tiny amount of genetic information is changed by imposing mutation in each child. This process must continue until termination condition is satisfied (Kannan et al., 2010).

Eventually, according to Dai and Zheng (2015), it was decided to use chance constrained programming method, Monte Carlo simulation and genetic algorithm to solve the presented model and this hybrid solution is shown in Fig. 2. Therefore, by using this hybrid method and MATLAB software, the presented model under uncertainty and risk parameters can be evaluated from perspectives of riskaverse and risk-seeking decision makers in random sizes. Due to evaluating different perspectives of decision makers, in this paper, conditional value at risk, sum of the excepted value and standard deviation are used for risk-averse and risk-seeking decision makers, respectively. The results in Table 10 are traceable. It is necessary to say that the calculated results in Table 10 have been obtained from the given data in Table 5 and Table 8 for different problem sizes represented in Table 9.

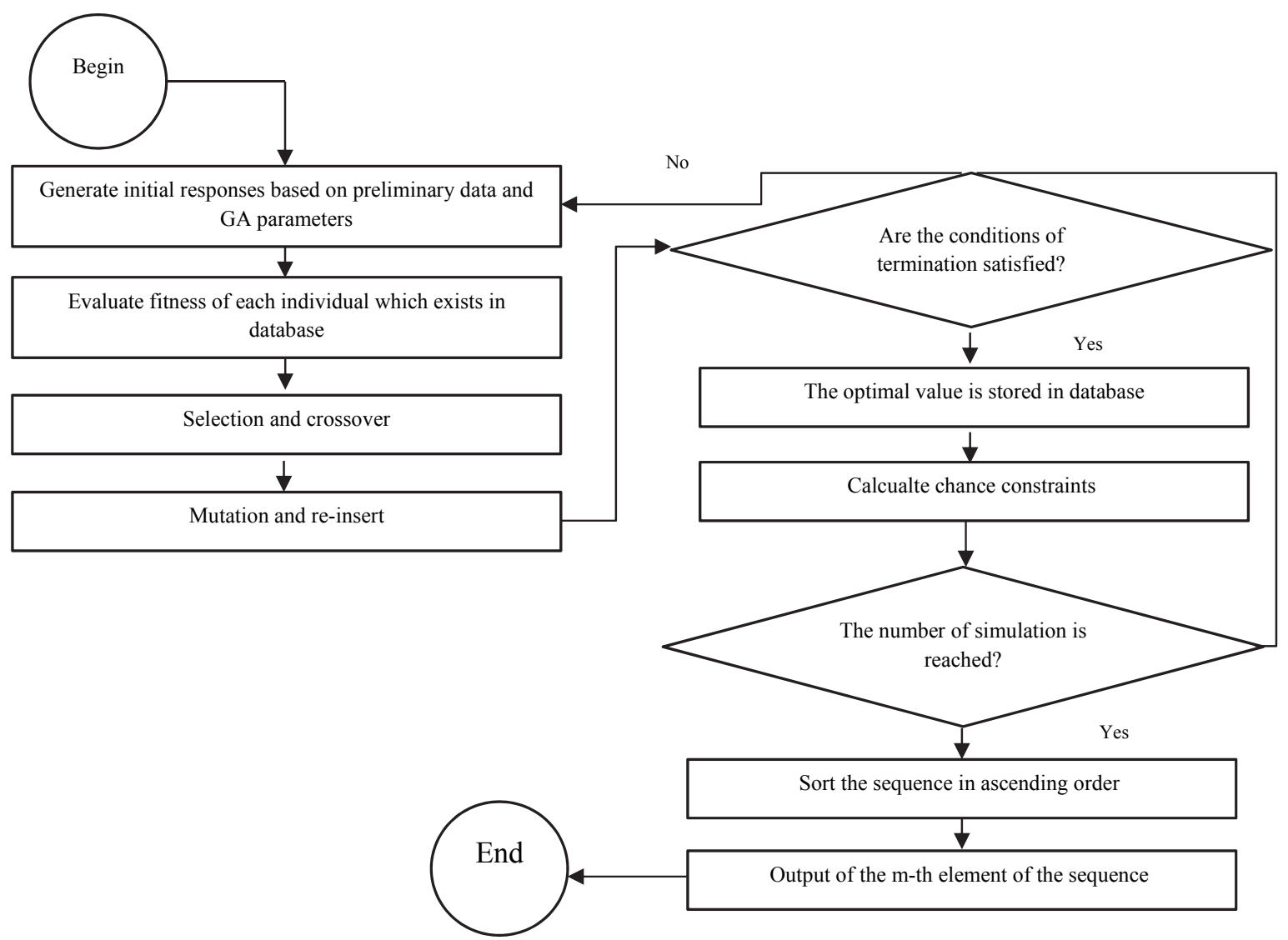

Table 8

Fig 2. Implementation of the proposed solution algorithm

Range of changes for the input stochastic data of MATLAB software

\begin{tabular}{clcl}
\hline Parameters & The amount attributed & parameters & The amount attributed \\
\hline$d e_{\text {chás }}^{T}$ & {$[80-115]$} & $\operatorname{rom}_{h m a_{1} s}^{T}$ & {$[0,1]$} \\
$x r_{\text {chás }}^{T}$ & {$[0,1]$} & $\operatorname{ror}_{h r a_{2} S}^{T}, \operatorname{rod}_{h d a_{3} s}^{T}$ & \\
\hline
\end{tabular}


Table 9

General information of the test problem to be solved by MATLAB software

\begin{tabular}{ccccccc}
\hline \multirow{2}{*}{$\begin{array}{c}\text { Number of } \\
\text { problem }\end{array}$} & $\begin{array}{c}\text { Recycling } \\
\text { centers }\end{array}$ & $\begin{array}{c}\text { Remanufacturing } \\
\text { centers }\end{array}$ & $\begin{array}{c}\text { HC.DA.RD } \\
\text { centers }\end{array}$ & Disposal & $\begin{array}{c}\text { Customer } \\
\text { zone }\end{array}$ & $\begin{array}{c}\text { Number } \\
\text { of } \\
\text { scenarios }\end{array}$ \\
\hline 1 & 3 & 4 & 3 & 3 & 2 & 2 \\
2 & 4 & 4 & 5 & 5 & 5 & 3 \\
3 & 10 & 13 & 15 & 10 & 15 & 3 \\
4 & 12 & 16 & 21 & 25 & 22 & 4 \\
5 & 23 & 28 & 31 & 25 & 31 & 5 \\
6 & 38 & 35 & 45 & 40 & 45 & 7 \\
\hline
\end{tabular}

Table 10

Results of the presented model under uncertainty and risk solved by MATLAB in different sizes

\begin{tabular}{|c|c|c|c|c|c|c|c|}
\hline & \multirow{2}{*}{$\begin{array}{l}\text { constraint } \\
\text { of locating }\end{array}$} & \multirow{2}{*}{$\begin{array}{l}\text { Number } \\
\text { of } \\
\text { problem }\end{array}$} & \multicolumn{5}{|c|}{ result } \\
\hline & & & $X_{\text {chás }}$ & $\alpha_{h m a_{1} s}$ & $\beta_{\mathrm{hra}_{2} \mathrm{~S}}$ & $\gamma_{h d a_{3} s}$ & $N S_{\text {chás }}$ \\
\hline \multirow{6}{*}{ Risk-averse } & \multirow{3}{*}{ yes } & 1 & 261.5605 & 32.7405 & 115.2174 & 113.6027 & 1754 \\
\hline & & 2 & 526.0582 & 182.9018 & 129.3934 & 213.7630 & 13133 \\
\hline & & 3 & 795.1832 & 374.9611 & 348.5060 & 71.7161 & 137670 \\
\hline & \multirow{3}{*}{ No } & 4 & 201730 & 24265 & 110660 & 66803 & 0 \\
\hline & & 5 & 524060 & 182560 & 166600 & 174900 & 0 \\
\hline & & 6 & 1540800 & 262720 & 676180 & 601950 & 0 \\
\hline \multirow{6}{*}{ Risk-seeking } & \multirow{3}{*}{ yes } & 1 & 295.3018 & 36.9640 & 130.0804 & 128.2575 & 1946 \\
\hline & & 2 & 704.5913 & 244.9748 & 173.3068 & 286.3097 & 14377 \\
\hline & & 3 & 1160 & 547.2351 & 508.6255 & 104.6657 & 152200 \\
\hline & \multirow{3}{*}{ No } & 4 & 223070 & 26832 & 122370 & 73870 & 0 \\
\hline & & 5 & 579470 & 201860 & 184210 & 193400 & 0 \\
\hline & & 6 & 1703400 & 290440 & 747520 & 665460 & 0 \\
\hline
\end{tabular}

The results of Table 9 also follow a trend similar to Table 6 for both kinds of decision makers. Also the results indicate that the risk-seeking decision maker gained more return products than risk-averse ones and it is not covered to any one that used returned products are more profitable and economical instead of producing new ones. Also, regardless of decision makers, the quantity of returned products to each remanufacturing, recycling and disposal centers do not have a specific trend and will be determined based on the quality of the used products, which are assumed to be uncertain, in any time that the program be run. Also total quantities of returned products to the chain were obtained from the summation quantities of remanufacturing, recycling and disposal centers. These results are shown clearly in Fig. 3.

Due to its crucial role in cost of reverse logistic, sensitivity analysis will be discussed on rate of return on the first size of Table 8. The results have been shown in Table 11 indicating that when rate of return increases, the returned products (first objective function) and total costs (second objective function) increase as well. 

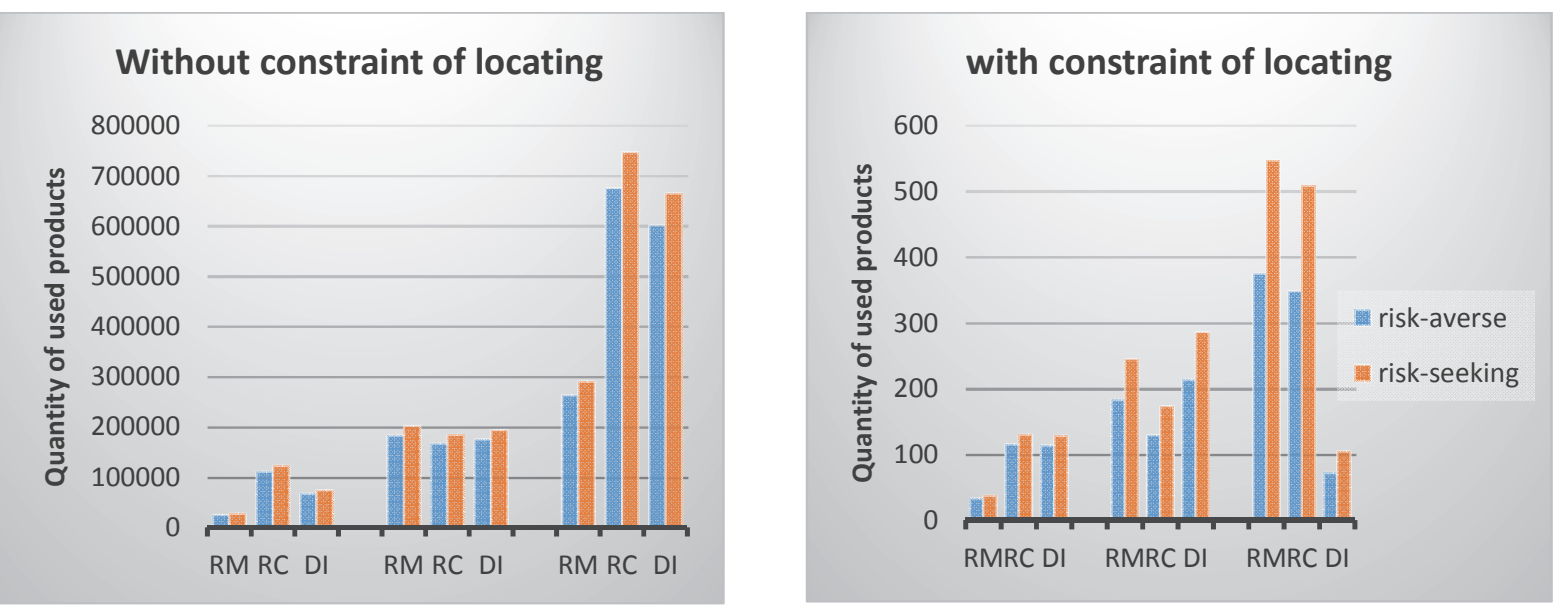

Fig 3. Comparison the quantity of used products shipped to different centers for being recovery, from the perspective of decision makers $(* \mathrm{RM}=$ remanufacture, $\mathrm{RC}=$ recycling $\& \mathrm{DI}=$ disposal $)$

Table 11

Results of rate of return sensitivity analysis for risk-averse and risk-seeking decision makers

\begin{tabular}{llcccccc}
\hline & Objective & \multicolumn{7}{c}{ Sensitive result } \\
\cline { 2 - 7 } & function & 0 & 0.2 & 0.4 & 0.6 & 0.8 & 1 \\
\hline \multirow{2}{*}{ Risk-seeking } & First obj. & 0 & 552 & 1104 & 1656 & 2208 & 2760 \\
& Second obj. & 2630 & 7808 & 12986 & 18163 & 23341 & 28519 \\
\hline \multirow{2}{*}{ Risk-averse } & First obj. & 0 & 524.4 & 1048 & 1573 & 2098 & 2622 \\
& Second obj. & 2630 & 7548 & 12468 & 17387 & 22305 & 27224 \\
\hline
\end{tabular}

\section{Conclusion and future research directions}

During the last few years, growing interest has been dedicated to reverse logistics, due to some reasons including responsibility about returned products, yielding more economic value and environmental concerns. Reverse logistics problem has always faced with uncertainty and risk due to their uncertain nature. Therefore, this paper considered simultaneously uncertainty and risk parameters in designing RL network. For solving the proposed model, chance constrained, genetic algorithm, and Monte Carlo simulations have been used together. At the end, the results have been evaluated and compared for riskaverse and risk-seeking decision makers by appropriate risk measures. The experimental results showed that reducing the cost has no serious impact on kind of decision makers and in most cases, risk-seeking decision maker gained more returned products than risk-averse ones.

There are some recommendations for further research: The model can be expanded to include others risk or uncertainty parameters such as capacity and variable costs or can compare the risk measures to each other. Future research can expanded this model by adding forward chain to this reverse presented structure to show better relation between the quantities of return products with profitability of chain. As a final offer, utilizing two-stage stochastic method instead of chance-constrained may lead to create valuable results.

\section{Reference}

Alumur, S. A., Nickel, S., Saldanha-da-Gama, F., \& Verter, V. (2012). Multi-period reverse logistics network design. European Journal of Operational Research, 220(1), 67-78.

Ayvaz, B., Bolat, B., \& Aydın, N. (2015). Stochastic reverse logistics network design for waste of electrical and electronic equipment. Resources, Conservation and Recycling, 104, 391-404.

Babazadeh, R., Jolai, F., \& Razmi, J. (2015). Developing scenario-based robust optimisation approaches for the reverse logistics network design problem under uncertain environments. International Journal of Services and Operations Management, 20(4), 418-440. 
Beamon, B. M. (1999). Designing the green supply chain. Logistics information management, 12(4), 332-342.

Benedito, E., \& Corominas, A. (2013). Optimal manufacturing policy in a reverse logistic system with dependent stochastic returns and limited capacities. International Journal of Production Research, 51(1), 189-201.

Charnes, A., \& Cooper, W. W. (1959). Chance-constrained programming. Management science, 6(1), 73-79.

Dai, Z., \& Zheng, X. (2015). Design of close-loop supply chain network under uncertainty using hybrid genetic algorithm: A fuzzy and chance-constrained programming model. Computers \& Industrial Engineering, 88, 444-457.

Diabat, A., Kannan, D., Kaliyan, M., \& Svetinovic, D. (2013). An optimization model for product returns using genetic algorithms and artificial immune system. Resources, Conservation and Recycling, 74, 156-169.

Ene, S., \& Öztürk, N. (2014). Open loop reverse supply chain network design. Procedia-Social and Behavioral Sciences, 109, 1110-1115.

Fleischmann, M., Krikke, H. R., Dekker, R., \& Flapper, S. D. P. (2000). A characterisation of logistics networks for product recovery. Omega, 28(6), 653-666.

Govindan, K., Paam, P., \& Abtahi, A. R. (2016). A fuzzy multi-objective optimization model for sustainable reverse logistics network design. Ecological Indicators, 67, 753-768.

Govindan, K., Soleimani, H., \& Kannan, D. (2015). Reverse logistics and closed-loop supply chain: A comprehensive review to explore the future. European Journal of Operational Research, 240(3), 603-626.

Jindal, A., Sangwan, K. S., \& Saxena, S. (2015). Network design and optimization for multi-product, multi-time, multi-echelon closed-loop supply chain under uncertainty. Procedia CIRP, 29, 656-661.

Kamjoo, A., Maheri, A., Dizqah, A. M., \& Putrus, G. A. (2016). Multi-objective design under uncertainties of hybrid renewable energy system using NSGA-II and chance constrained programming. International Journal of Electrical Power \& Energy Systems, 74, 187-194.

Kannan, G., Sasikumar, P., \& Devika, K. (2010). A genetic algorithm approach for solving a closed loop supply chain model: A case of battery recycling. Applied Mathematical Modelling, 34(3), 655670.

Kara, S. S., \& Onut, S. (2010). A two-stage stochastic and robust programming approach to strategic planning of a reverse supply network: The case of paper recycling. Expert Systems with Applications, 37(9), 6129-6137.

Khatami, M., Mahootchi, M., \& Farahani, R. Z. (2015). Benders' decomposition for concurrent redesign of forward and closed-loop supply chain network with demand and return uncertainties. Transportation Research Part E: Logistics and Transportation Review, 79, 1-21.

Lee, D. H., \& Dong, M. (2009). Dynamic network design for reverse logistics operations under uncertainty. Transportation Research Part E: Logistics and Transportation Review, 45(1), 61-71.

Lieckens, K., \& Vandaele, N. (2007). Reverse logistics network design with stochastic lead times. Computers \& Operations Research, 34(2), 395-416.

Min, H., Ko, H. J., \& Ko, C. S. (2006). A genetic algorithm approach to developing the multi-echelon reverse logistics network for product returns. Omega, 34(1), 56-69.

Mitra, K., Gudi, R. D., Patwardhan, S. C., \& Sardar, G. (2008). Supply Chain Planning under Uncertainty: A Chance Constrained Programming Approach. IFAC Proceedings Volumes, 41(2), 10570-10575.

Nikolaou, I. E., Evangelinos, K. I., \& Allan, S. (2013). A reverse logistics social responsibility evaluation framework based on the triple bottom line approach. Journal of Cleaner Production, 56, 173-184.

Pishvaee, M. S., Rabbani, M., \& Torabi, S. A. (2011). A robust optimization approach to closed-loop supply chain network design under uncertainty. Applied Mathematical Modelling, 35(2), 637-649.

Pokharel, S., \& Mutha, A. (2009). Perspectives in reverse logistics: a review. Resources, Conservation and Recycling, 53(4), 175-182. 
Roghanian, E., \& Pazhoheshfar, P. (2014). An optimization model for reverse logistics network under stochastic environment by using genetic algorithm. Journal of Manufacturing Systems, 33(3), 348356.

Salema, M. I. G., Barbosa-Povoa, A. P., \& Novais, A. Q. (2007). An optimization model for the design of a capacitated multi-product reverse logistics network with uncertainty. European Journal of Operational Research, 179(3), 1063-1077.

Soleimani, H., \& Govindan, K. (2014). Reverse logistics network design and planning utilizing conditional value at risk. European Journal of Operational Research, 237(2), 487-497.

Soleimani, H., \& Kannan, G. (2015). A hybrid particle swarm optimization and genetic algorithm for closed-loop supply chain network design in large-scale networks. Applied Mathematical Modelling, 39(14), 3990-4012.

Tonanont, A., Yimsiri, S., Jitpitaklert, W., \& Rogers, K. J. (2008, January). Performance evaluation in reverse logistics with data envelopment analysis. In IIE Annual Conference. Proceedings (p. 764). Institute of Industrial Engineers-Publisher.

Tuzkaya, G., Gülsün, B., \& Önsel, Ş. (2011). A methodology for the strategic design of reverse logistics networks and its application in the Turkish white goods industry. International Journal of Production Research, 49(15), 4543-4571.

Vahdani, B., \& Mohammadi, M. (2015). A bi-objective interval-stochastic robust optimization model for designing closed loop supply chain network with multi-priority queuing system. International Journal of Production Economics, 170, 67-87.

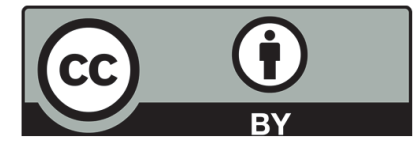

(C) 2018 by the authors; licensee Growing Science, Canada. This is an open access article distributed under the terms and conditions of the Creative Commons Attribution (CC-BY) license (http://creativecommons.org/licenses/by/4.0/). 